\title{
Candy-plug technique for ruptured chronic type B aortic dissection
}

\section{Akimasa Morisaki, Etsuji Sohgawa, Noriaki Kishimoto, Kokoro Yamane, Toshihiko Shibata}

\begin{tabular}{|c|l|}
\hline Citation & Asian Cardiovascular and Thoracic Annals. 27(9); 770-772 \\
\hline Issue Date & 2019-11-01 \\
\hline Type & Journal Article \\
\hline Textversion & Author \\
\hline Rights & $\begin{array}{l}\text { The following article has been accepted by Asian Cardiovascular and Thoracic Annals. } \\
\text { After it is published, it will be found at https://doi.org/10.1177/0218492319853734. } \\
\text { This article may be downloaded for personal use only. Any other use requires prior } \\
\text { permission of SAGE Publications. }\end{array}$ \\
\hline DOI & \begin{tabular}{l}
$10.1177 / 0218492319853734$ \\
\hline
\end{tabular} \\
\hline
\end{tabular}

Self-Archiving by Author(s) Placed on: Osaka City University Repository 


\section{Endovascular Repair with Candy-plug Technique for Ruptured Chronic type B Aortic}

\section{Dissection}

Akimasa Morisaki, MD, $\mathrm{PhD}^{1 *}$, Etsuji Sohgawa, $\mathrm{MD}^{2}$, Hiromichi Fuji, $\mathrm{MD}, \mathrm{PhD}^{1}$, Yosuke Takahshi, $\mathrm{MD}, \mathrm{PhD}^{1}$, Noriaki Kishimoto, $\mathrm{MD}^{1}$, Kokoro Yamane, $\mathrm{MD}^{1}$, and Toshihiko Shibata, $\mathrm{MD}, \mathrm{PhD}^{1}$

${ }^{1}$ Department of Cardiovascular Surgery, Osaka City University Graduate School of Medicine, Osaka, Japan

${ }^{2}$ Department of Diagnosis and Interventional Radiology, Osaka City University Graduate School of Medicine, Osaka, Japan

*Corresponding author: Akimasa Morisaki, MD, PhD

Department of Cardiovascular Surgery, Osaka City University Graduate School of Medicine 1-4-3 Asahimachi, Abeno-ku, Osaka 545-8585, Japan

Tel: +81-6-6645-3980; Fax: +81-6-6646-3071; E-mail: m3_514@yahoo.co.jp

\section{Word count:}

Manuscript Types: Case report

Running title: Candy plug technique for ruptured aortic dissection 


\begin{abstract}
Surgical repair has conventionally been performed for ruptured chronic type B aortic dissection, but its mortality rate is very high. The candy-plug technique has been applied for occlusion of the false lumen in chronic type B aortic dissection with good long-term results. However, few reports have described this technique for ruptured chronic type B aortic dissection. A 62-year-old man with ruptured chronic type B aortic dissection (DeBakey type IIIb) was transferred to our hospital on an emergency basis. Computed tomography angiography showed that the dissecting aorta consisted of a patent false lumen with a ruptured proximal descending aorta, distal aortic arch entry, and mediastinal hematoma. Debranching endovascular repair was performed with the candy-plug technique, resulting in successful occlusion of the false lumen of the ruptured aortic dissection. The patient was discharged uneventfully, and the false lumen of the descending aorta gradually decreased without endoleakage.
\end{abstract}

Keywords: Candy-plug technique, Endovascular repair, Ruptured chronic type B aortic dissection 


\section{Introduction}

Ruptured chronic type B aortic dissection has conventionally been treated by open repair, which is associated with high mortality and morbidity. Cases of endovascular repair with occlusion of the false lumen for ruptured chronic type B aortic dissection have recently been reported with good early results [1]. Recently, the candy-plug technique for occlusion of the false lumen in type B dissecting aortic aneurysm has been reported [2]. However, few reports have described this technique for ruptured aortic dissection. We experienced a case of successful endovascular repair with the candy-plug technique to treat ruptured chronic type B aortic dissection.

\section{Case Report}

A 62-year-old man was transferred to our hospital on an emergency basis because of back pain. He had previously been diagnosed with chronic type B aortic dissection (DeBakey type IIIb) that consisted of a patent false lumen with distal aortic arch entry. Emergent CT angiography showed that the ruptured chronic type B aortic dissection had a new false lumen of the descending aorta, the descending aorta had dilated to $56 \mathrm{~mm}$, and a mediastinal hematoma had formed (Figure 1).

Therefore, we considered an emergency endovascular repair with the candy-plug technique that involving occlusion of the entry of the distal aortic arch and false lumen of the distal descending aorta.

After anesthetic induction, hemodynamic instability developed with requiring a massive transfusion. Immediately, we performed thoracic endovascular repair with a Conformable GORE ${ }^{\circledR}$ $\mathrm{TAG}^{\circledR}$ Thoracic Endoprosthesis (proximal: 34-mm diameter, distal: 28-mm diameter; W.L. Gore \& Associates, Inc., Flagstaff, AZ) from distal to the brachiocephalic artery to the descending aorta above the celiac artery via the right common femoral artery. Deployment of the stent graft that occluded the entry stabilized the patient's hemodynamics. Next, we occluded the false lumen above the celiac artery by the candy-plug technique with an aortic extender $\left(\right.$ GORE $^{\circledR}$ EXCLUDER $^{\circledR}$ AAA Endoprosthesis, 32-mm diameter; W.L. Gore \& Associates, Inc.) and an AMPLATZER ${ }^{\mathrm{TM}}$ Vascular $^{2}$ Plug II (16-mm diameter; Abbott Laboratories, Chicago, IL) via the left femoral artery. We then administered 4000 units of heparin because of the patient's thrombotic tendency. Finally, we 
performed a left common carotid artery to left axillary artery bypass with coil embolization of the proximal left subclavian artery.

The patient was extubated on postoperative day 2 without brain damage or paraplegia, and uneventfully discharged on postoperative day 13 . Follow-up CT angiography showed shrinkage of the thrombosed false lumen and mediastinal hematoma without endoleakage (Figure 2).

\section{Discussion}

Recently, the candy-plug technique for occlusion of the false lumen in type B dissecting aortic aneurysm has shown high feasibility and effectiveness with good shrinkage or remodeling of the dissected aorta [3]. However, Ogawa et al. indicated the risk of major problems including narrowing of the true lumen by compression of the candy-plug stent and flap or vessel wall injury by the stent. Therefore, Kotani et al. [4] described a modified candy-plug technique that involves deploying the stent graft in the true lumen at the same distal end of the occluder device in the false lumen. We also used this modified candy-plug technique for ruptured chronic type B aortic dissection in the present case, which provided good early results.

Several techniques for occlusion of the false lumen or re-entry have been reported, such as coil embolization, the candy-plug technique, covered stents with the chimney technique, and others. For ruptured aneurysms, a simple and easy technique may be favorable to immediately achieve hemodynamic stability. Therefore, the simplicity of the candy-plug technique may be favored over coil embolization and use of a covered stent with the chimney technique. Moreover, the anatomical findings by CT angiography are an important factor indicating whether the false lumen can be occluded by the candy-plug technique. If the patient has a dilated false lumen larger than the size of the commercialized covered stent graft at the distal descending aorta, the candy-plug technique may be difficult due to endoleakage.

\section{Conclusion}

Endovascular repair with the candy-plug technique may be a feasible and useful treatment for ruptured chronic type B aortic dissection. 
Disclosure Statement: The authors have no conflicts of interest of declare.

Acknowledgment: We thank Angela Morben, DVM, ELS, from Edanz Group (www.edanzediting.com/ac), for editing a draft of this manuscript. 


\section{References}

1) Marone EM, Leopardi M, Bertoglio L, Mascia D, Chiesa R. Original off-label endovascular solution to occlude false lumen rupture in chronic type B aortic dissection. Ann Vasc Surg 2017;40:299.e1-5.

2) Kolbel T, Lohrenz C, Kieback A, Diener H, Debus ES, Larena-Avellaneda A. Distal false lumen occlusion in aortic dissection with a homemade extra-large vascular plug: the candy-plug technique. J Endovasc Ther 2013;20:484-9.

3) Ogawa Y, Nishimaki H, Chiba K, Murakami K, Sakurai Y, Fujiwara K, et al. Candy-plug technique using an Excluder aortic extender for distal occlusion of a large false lumen aneurysm in chronic aortic dissection. J Endovasc Ther 2016;23:483-6.

4) Kotani S, Inoue Y, Kasai M, Suzuki S, Hachiya T. Modified 'candy-plug' technique for chronic type B aortic dissection with aneurysmal dilatation: a case report. J Cardiothorac Surg $2017 ; 12: 77$. 


\section{Figure Legends}

Figure 1. Preoperative computed tomography angiography. (A) Three-dimensional computed tomography. (B, C) Axial image. Solid arrow indicates the entry of the distal aortic arch. Broken arrow indicates the rupture site of the false lumen in the descending aorta with a hematoma. 
Figure 1

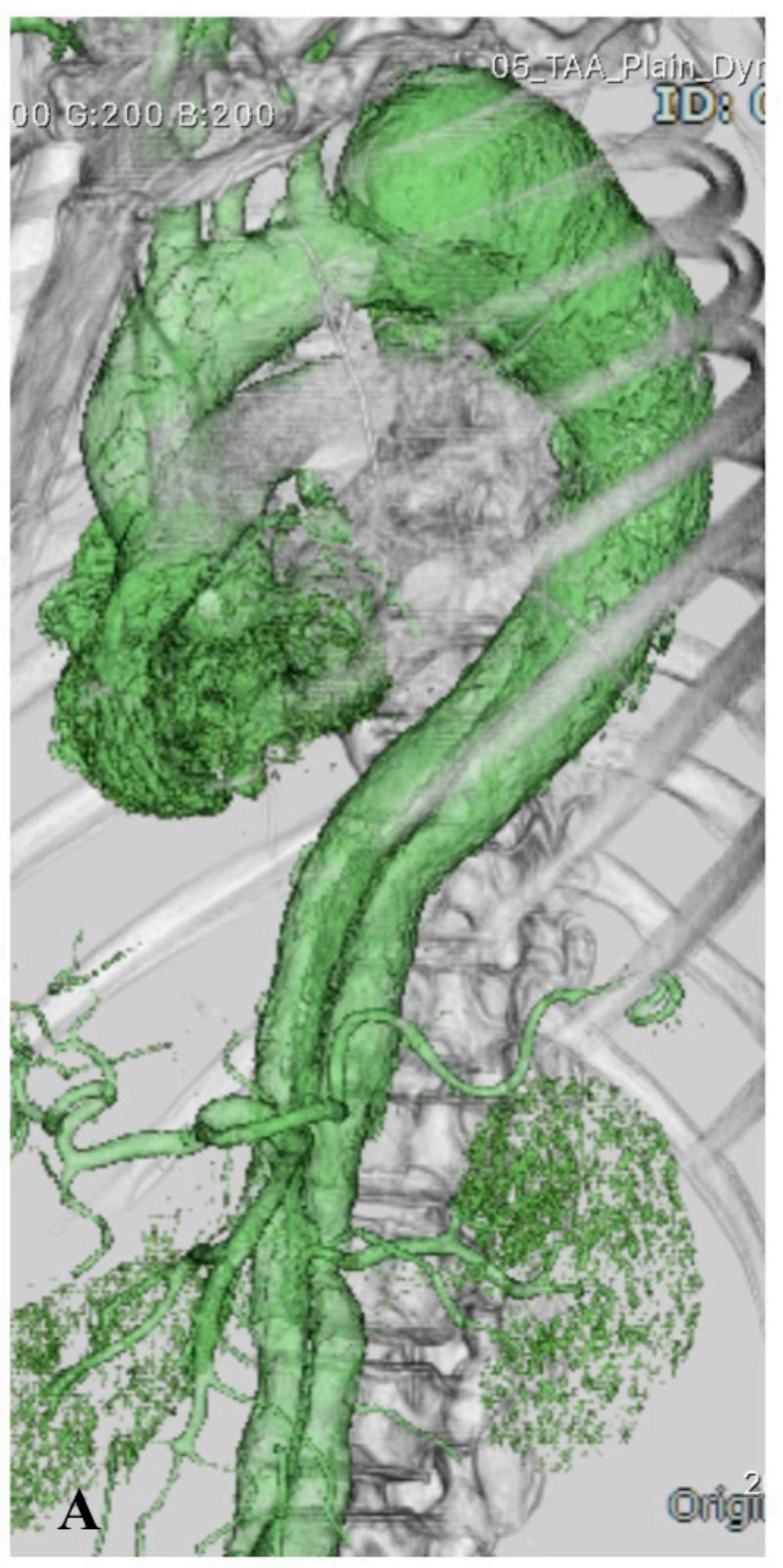

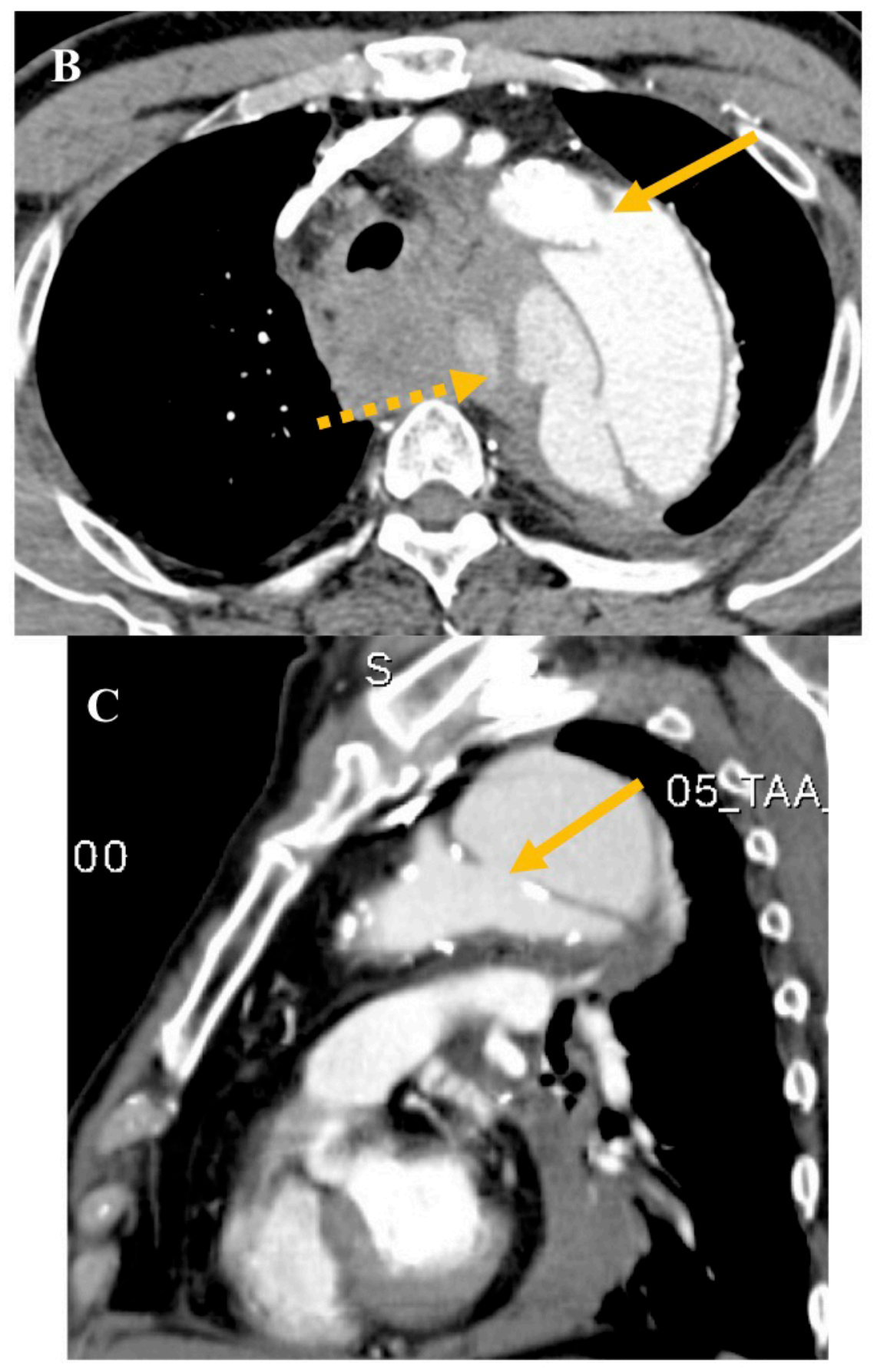


Figure 2. Computed tomography angiography 3 months postoperatively. (A) Three-dimensional computed tomography. (B, C) Axial image. Solid arrow indicates the candy-plug stent. 
Figure 2
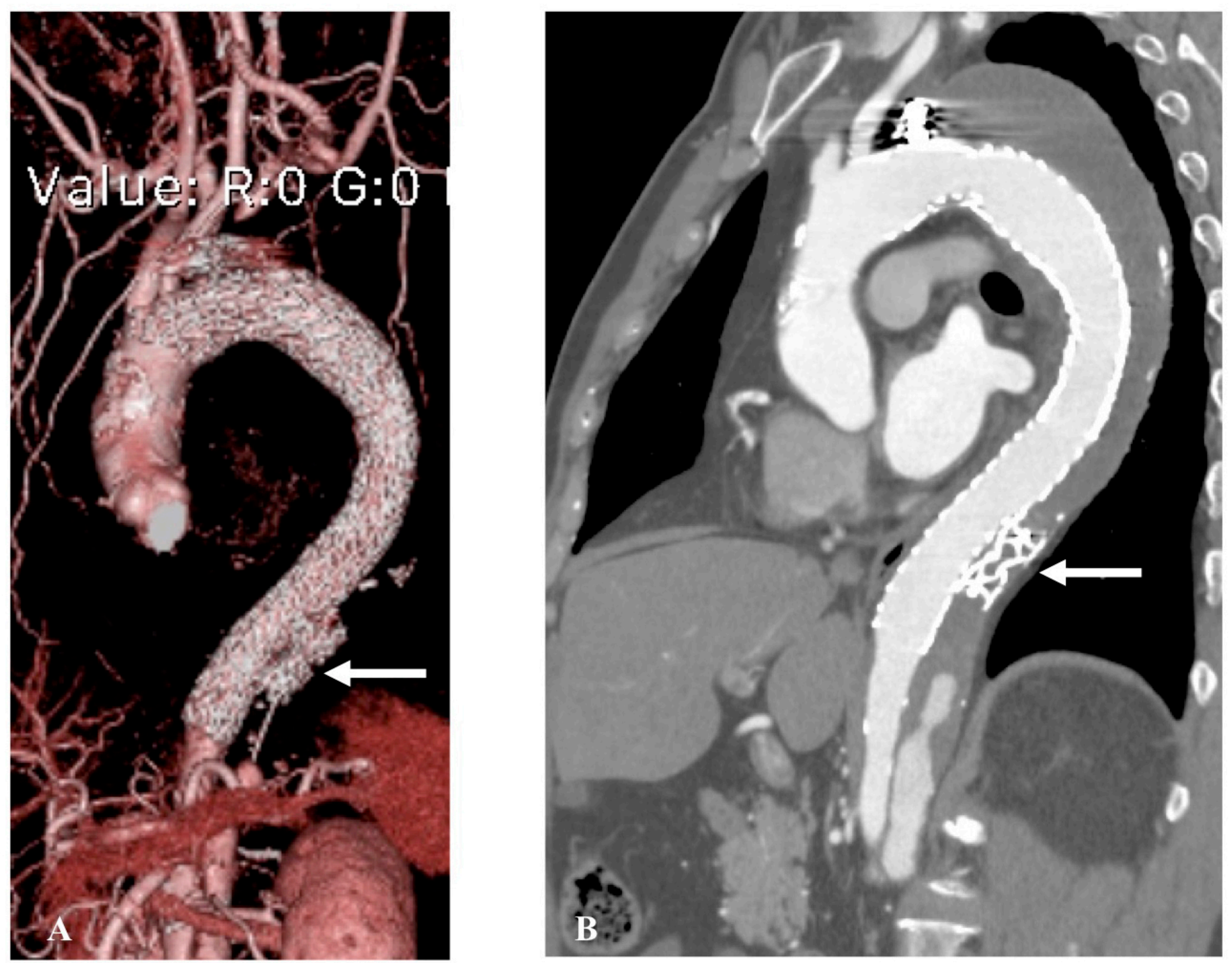